\title{
UTILIZACIÓN AGRARIA DEL SUELO EN LAS \\ COMARCAS DE ALICANTE
}

\author{
Cipriano Juárez Sánchez-Rubio
}

\section{1.- FUENTE, MÉTODO Y VALIDEZ GEOGRÁFICA}

El Ministerio de Agricultura da a conocer mediante sus Anuarios los distintos aprovechamientos agrarios de cada provincia y los rendimientos que de ellos se obtienen. El mismo Ministerio ofrece también los datos municipales agrupados según las comarcas agrarias de las distintas provincias y bajo el epígrafe de «Análisis de la Producción Vegetal a nivel Comarcal» ${ }^{1}$. Éste determina para cada comarca lo siguiente: utilización de la tierra, características agrícolas (secano, regadío, cultivos herbáceos y leñosos), rendimientos de los cultivos, precios, producción y valor productivo de cada uno, caracterización de cada comarca a base de índices, agrupación por su analogía y problemática de cada uno de ellos. Otra parte ofrece las características ganaderas con el número de cabezas, peso en vivo, régimen (extensivo, intensivo o mixto) de explotación del ganado y su utilización cárnica o lechera, pero sólo referida al lanar y vacuno. La última parte estadística hace referencia a las dimensiones de las explotaciones, número de las mismas en cada intervalo, grado de mecanización (tractores, cosechadoras, motocultores y caballos de vapor que totalizan en cada caso) y el precio de las hectáreas de secano y regadío, tanto en venta como en renta. El Análisis finaliza con la relación de términos municipales integrados en cada comarca.

Además de estos Análisis comarcales que se realizan por provincias, el Ministerio ha publicado el de los conjuntos regionales españoles basados en la misma metodología y criterios, incluyendo los mismos cuadros indicativos, de lo que se deduce la idoneidad o la marginalidad de los cultivos en las distintas comarcas. [68]

La finalidad de la fuente presente es obtener mediante una serie de estudios analíticos un conocimiento lo más próximo posible a la realidad, sobre la dedicación y utilización de la tierra en las distintas comarcas del país. Los datos básicos corresponden a los años agrícolas de 1974 y 1975. Las respectivas superficies son extraídas de los boletines denominados «Superficie ocupada por los cultivos agrícolas» (1-T), cumplimentados a nivel municipal por las Cámaras Agrarias a instancia del Ministerio. Posteriormente, estos datos se han depurado y elaborado por los Servicios Técnicos de las Delegaciones Provinciales del Ministerio, de acuerdo con sus criterios y la experiencia e información acumulada en los mismos. Además en aquellas provincias donde se encuentra avanzada la realización del programa de «Evaluación de Recursos Agrarios» se han podido mejorar las estadísticas disponibles, incorporando los datos que proporcionan los «Mapas de cultivo y Aprovechamientos $^{2}$ y los «Inventarios Agronómicos» finalizados en 1977. Por último, los datos de rendimiento y producción proceden de las estimaciones efectuadas por los Servicios Técnicos de las Delegaciones Provinciales.

\footnotetext{
${ }^{1}$ JUÁREZ SÁNCHEZ-RUBIO, C. «Diferencias comarcales salmantinas según el Análisis vegetal». Estudios Geográficos, 1978, no 150, pp. 99-105.

2 JUÁREZ SÁNCHEZ-RUBIO, C. «Mapa de cultivos y Aprovechamiento a escala 1:50.000». Estudios Geográficos, 1976, nº 144, pp. 360-362.
} 
Su metodología es como sigue: el total de la superficie física se fracciona en dos conjuntos, superficie improductiva (terrenos que no tienen aprovechamiento alguno) y productiva (incluye todos los terrenos agrícolas o forestales que tienen algún tipo de producción agraria, se labren o no se labren). La superficie productiva equivale a la no labrada y labrada. La no labrada engloba a las dehesas, montes moderables y monte bajo, praderas naturales, pastizales, matorrales y espartizales. Superficie labrada es la que se cultiva con intensidad igual o superior al tercio.

Al mismo tiempo y con objeto de una posterior agrupación comarcal en base a su analogía se define una serie de índices (cuadro $\mathrm{n}^{\mathrm{o}}$ 1) que permiten clasificar las comarcas en ganaderas o agrícolas. Si el índice es superior al 50\% la comarca queda englobada en uno de los dos conceptos. Además, en las comarcas agrícolas se calculan también los índices de aprovechamiento agrícola dominante, regadío, barbecho, mecanización y rendimiento bruto por hectárea de superficie labrada. [69]

Las comarcas agrícolas se agrupan en primer lugar, por el valor del Índice Agrícola para los intervalos 40-60, 60-80 y 80-100. Dentro de cada intervalo se agrupan según el Aprovechamiento Agrícola Dominante en base a dos niveles: el primero, cuando el aprovechamiento supone más del 75\% de la superficie labrada; y el otro, cuando no se alcanza dicho porcentaje. También para cada grado de aprovechamiento se consideran diferentes niveles de intensidad de regadío según el porcentaje acaparado por dicha superficie respecto a la labrada: más del $70 \%$, entre el 20 y el $40 \%$ y menos del $20 \%$. Por último, la intensidad del barbecho queda realizada según los siguientes niveles: más del $50 \%$ de la superficie labrada en el barbecho blanco; entre el 30 y el 50\% y menos del 30\%.

Con frecuencia los datos de nuestras fuentes agrarias vienen siendo reproducidos y utilizados sin un análisis previo y sólo en algunas ocasiones poniendo en duda la validez de los resultados obtenidos. Entonces cabe preguntarse ¿Cuál es su límite de validez geográfico?

En primer lugar, tales índices sólo nos reflejan la mayor o menor importancia de cada uno de los epígrafes manejados (secano, regadío, barbecho, etc.), y, en ningún caso nos definen la aptitud de cada comarca para ese cultivo o dedicación. E1 segundo es que, son de régimen interno, es decir, no tienen difusión alguna. El tercero que, al utilizarse el mismo esquema para todas las provincias no siempre se recogen los detalles propios de cada una de ellas. Así, en el caso concreto de la de Alicante no aparecen diferenciados los tipos temporales de la patata, las variaciones de almendra, los cultivos de invernadero (pimiento, alcachofas, tomate, melón y recientemente flores), la superficie ocupada por cada uno de ellos, sus rendimientos, precios, propiedad y régimen de tenencia de los mismos. Son circunstancias muy necesarias de destacar en este sector de la fachada mediterránea, ya que la diferencia de valor en los productos no recogidos por los servicios estatales, -y en la provincia son poquísimos los productos con precios garantizados- provocan claras desigualdades de renta que perjudican a las áreas más marginales. El cuarto, y, puesto que el análisis ofrece la estructura de las explotaciones, hubiera sido de gran interés para esta zona el incluir también la distribución de la agricultura a tiempo parcial, ya que el agricultor alicantino dedica a otra actividad más de la mitad de su tiempo, mientras consigue un producto bruto muy elevado en relación con éste y la superficie que cultiva. En quinto lugar, los rendimientos ofrecidos por el Análisis no deberían ser estimados por los servicios técnicos, sino los elaborados por las Cámaras Agrarias a través de las declaraciones de los agricultores, a pesar de que no reflejen exactamente las verdaderas producciones. Ello evitaría que en alguno de 
estos trabajos, los rendimientos [70] aumentaran de un año a otro porcentajes iguales en todas sus comarcas para los mismos cultivos. Por último, lo que es más lamentable, sólo se han elaborado los informes señalados, interrumpiéndose después el trabajo, ya que el de 1977 no puede ser considerado como tal al modificarse la extensión comarcal y quedar enmascarado bajo el epígrafe «Otros cultivos» algunos de gran importancia provincial. A pesar de todo, creemos que para un estudio a nivel regional propio es una buena fuente, quizás la única «que permita la visión más completa de la personalidad agraria de cada comarca y los tipos de paisajes resultantes que se deducen de la confrontación de todas» ${ }^{3}$.

\section{2.- LA COMARCALIZACIÓN ADMINISTRATIVA AGRARIA}

La fragmentación comarcal se acomoda a los límites provinciales y municipales, ya que con arreglo a ellos se recogen y ofrecen siempre los datos estadísticos. Sin embargo, no existe correspondencia exacta entre las divisiones realizadas por geógrafos y economistas y las propuestas, varios años después, por el Ministerio de Agricultura ${ }^{4}$. En tal sentido, dicho organismo parcela la provincia de Alicante en una serie de comarcas que puede resultar insatisfactoria, pero que no se debe prescindir de ella porque aprovechamientos agrarios y rendimientos, aunque se relacionen con hechos humanos presentes y pasados, están condicionados también por los caracteres físicos (Fig. 1).

La provincia abarca una superficie de $5819 \mathrm{~km} 2$ y la fraccionan en diez pequeñas unidades cuyas extensiones oscilan entre las 97.345 hectáreas de Orihuela y las 27.836 de Callosa de Ensarriá. En realidad, la división administrativa agraria se ajusta, en su casi totalidad, a la propuesta por Rosselló. Sin embargo, frente a su planteamiento de una «estructura a base de nueve grandes comarcas, dos de las cuales son susceptibles de una clara visión, el Marquesat y la Marina, por una razón $\mathrm{u}$ otra $»^{5}$, se presenta la ministerial de las diez.

La diferencia estriba no sólo en su número sino en la extensión de las [71] mismas. Así, la Hoya de Castalla que aparece como una de las comarcas mejor delimitadas de la provincia desde los factores físicos, desaparece totalmente en la división administrativa agraria, al tiempo que a sus municipios se les integra en las comarcas próximas, en la forma siguiente: Alcoy incorpora a Ibi, Villena a Castalla y Onil, y Alicante, a Tibi. En cambio, en la división ministerial las comarcas tradicionales del Marquesat y la Marina aparecen fraccionadas originando dos

\footnotetext{
${ }^{3}$ CABO ALONSO, A. «Las regiones del interior de España» en Los paisajes rurales de España. Asociación de Geógrafos Españoles. Valladolid, 1980. pág. 120.

${ }^{4}$ LÓPEZ GÓMEZ, A. «La Región Valenciana», en TERAN, M. de Geografía de España y Portugal. Montaner y Simón. Barcelona, 1967 ROSELLÓ VERGER, V. Mª «Ensayo de una división comarcal de la provincia de Alicante». Cuadernos de Geografía, 1965, no 1, pp. 158-177. PÉREZ PUCHAL, P. «La comarcalització del territori valencià» en Taula Redona sobre la comarcalització al País Valencià. Diputación Provincial de Valencia. Valencia, 1980, pp. 41-47.

${ }^{5}$ ROSSELLÓ, V.Ma . «Ensayo de una...», op. cit., pág. 171.
} 


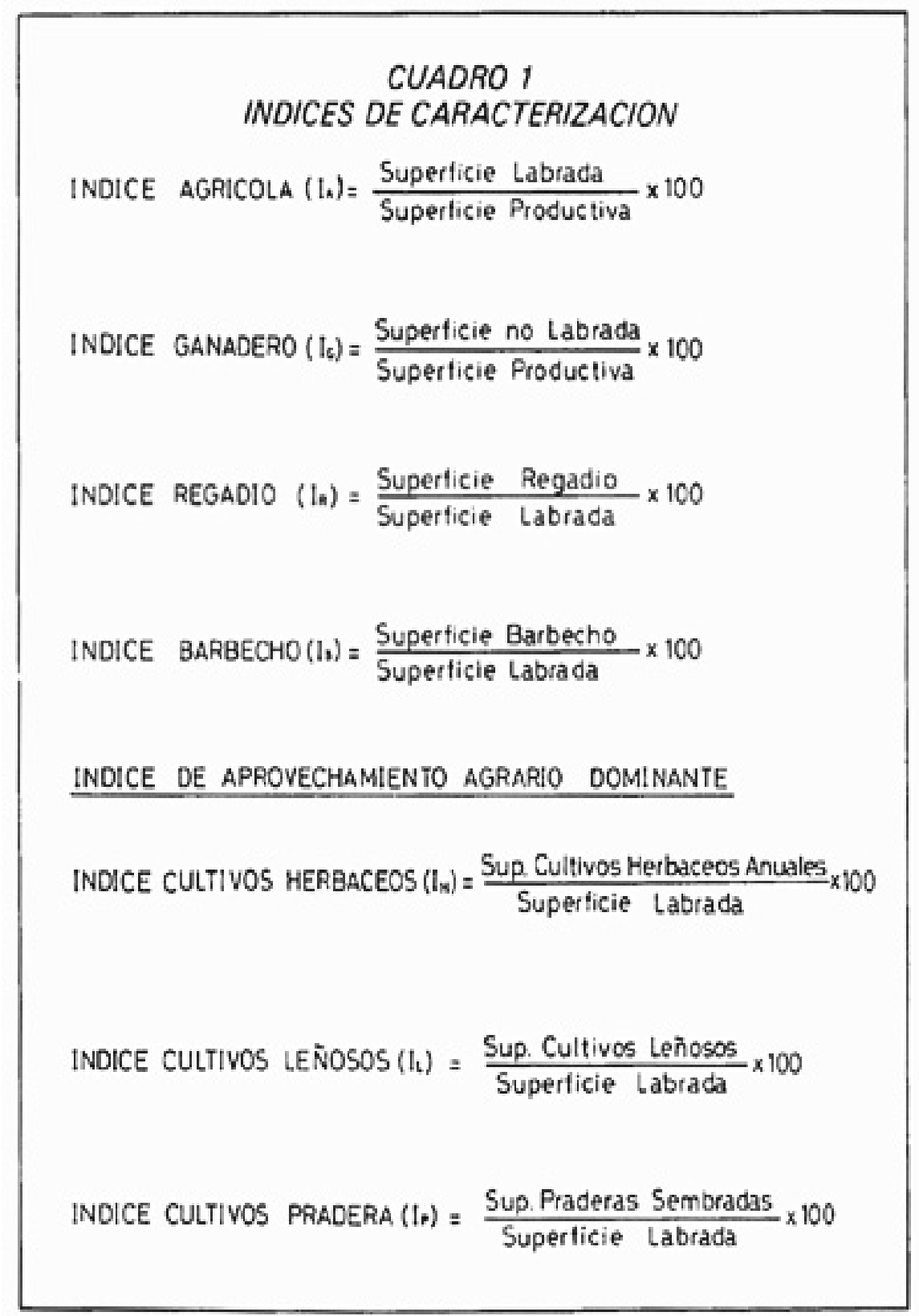

nuevas comarcas [72]: Pego y Callosa de Ensarriá. En realidad, son las subdivisiones indicadas por Rosselló y que pudieron constituir dos subcomarcas, aunque en el caso de la Marina «esta parte montuosa no tiene suficiente peso demográfico y económico para constituirse como tal» ${ }^{6}$.

En la provincia se distinguen, además de la que lleva el nombre de la capital con una extensión de 67.348 hectáreas, nueve comarcas con distinta superficie. También, las denominaciones son diferentes pues el sistema elegido hace referencia al núcleo urbano más importante incluido en ellas: Alcoy con 68.447 hectáreas, Villena 80.542, Novelda 86.101, Pego 31.960, Denia 43.961, Callosa de Ensarriá 27.836, Villajoyosa 29.661, Elche 48.700 y Orihuela con 97.345 hectáreas. Sin embargo, tal división no es continuada por el Análisis de 1977 que pretendía actualizar los resultados de los años 1974 y 1975.

${ }^{6}$ ROSSELLÓ, V.Mª «Ensayo...», op. cit., pág. 174. 
Ahora, las delimitaciones seguidas son las propuestas en la publicación de la Secretaría Técnica ${ }^{7}$, que subdivide a la provincia, a efectos agrarios, en cinco comarcas cuya extensión y denominación varían nuevamente ${ }^{8}$. Por ello, tal comarcalización elegida impide realizar la evolución producida en cada una de las mismas durante dicho período, pudiéndose comprobar su evolución, solamente, a escala provincial y reducida a la superficie productiva, improductiva y labrada.

\section{3.- FACTORES LIMITATIVOS DE LA PRODUCCIÓN}

El medio físico provincial plantea inconvenientes y ofrece posibilidades de aprovechamiento agrario del suelo. En gran parte de las tierras de más fácil roturación su mayor dificultad física radica en el acusado predominio de una pluviometría insuficiente, en la elevada irregularidad interanual y estacional y, sobre todo, en la falta de concordancia de éstas y la temperatura (Cuadro 2).

En líneas generales, se considera al clima provincial como mediterráneo, pero la suavidad del invierno se altera por el relieve, la continentalidad y la altitud. Se distinguen dos zonas: la costera, con media anual entre 17 y $19^{\circ}$; y las sierras y llanos interiores, por encima de los 400m. de altitud, con media que oscila entre 13 y $17^{\circ}$. Sin embargo, «la diferencia [73] mayor estriba entre el invierno frío y el suave que,

\footnotetext{
${ }^{7}$ MINISTERIO DE AGRICULTURA, SECRETARÍA GENERAL TÉCNICA. Codificación a efectos agrarios de regiones, provincias y comarcas. Madrid, 1972.

${ }^{8}$ DIRECCIÓN GENERAL DE LA PRODUCCIÓN AGRARIA. Análisis de la Producción Vegetal a nivel comarcal. Región Agraria VII. Levante. Madrid, 1977, pp. 140.
} 


\section{CUADRO 2}

VILLENA

Tipologia: $\mathrm{DB}_{2} \mathrm{db}_{4}$

T. media

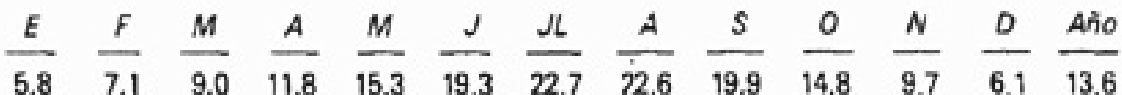
$\begin{array}{llllllllllllll}\text { ETP } & 2,7 & 17,6 & 27,8 & 46,2 & \mathbf{7 7 , 5} & 104,2 & 135,0 & 126,4 & 93,6 & 57,6 & 27,7 & 12,5 & 738,8\end{array}$ $\begin{array}{llllllllllllll}\text { Precip. } & 28,1 & 20,0 & 26,9 & 41,7 & 43,3 & 32,6 & 5.1 & 16,2 & 36,9 & 61,6 & 30,6 & 35,8 & 378,8\end{array}$ $\begin{array}{llllllcccccccc}\text { Déficit } & 0 & 0 & 0 & 0 & 0 & 63,2 & 129,9 & 110,2 & 56,7 & 0 & 0 & 0 & 360,0 \\ \text { Superávit } & 0 & 0 & 0 & 0 & 0 & 0 & 0 & 0 & 0 & 0 & 0 & 0 & 0\end{array}$

\begin{tabular}{|c|c|c|c|c|c|c|c|c|c|c|c|c|c|}
\hline & \multirow[b]{2}{*}{$E$} & \multicolumn{4}{|c|}{ ALCOY } & \multirow[b]{2}{*}{$J$} & \multirow[b]{2}{*}{$J$} & \multicolumn{6}{|c|}{ Tipologia: $\mathrm{DB}^{\prime}, \mathrm{db}_{4}$} \\
\hline & & $F$ & $M$ & $A$ & $M$ & & & $A$ & $s$ & 0 & $N$ & 0 & Año \\
\hline T. Media & 7.4 & 8.1 & 10,9 & 11,9 & 16,4 & 20,0 & 24,0 & 24,0 & 20,6 & 15,3 & 10,8 & 8,2 & 14,8 \\
\hline ETP & 18 & 18 & 37 & 47 & 77 & 108 & 147 & 138 & 97 & 55 & 30 & 20 & 792 \\
\hline Precip. & 49 & 40 & 39 & 51 & 28 & 31 & 5 & 10 & 35 & 86 & 40 & 65 & 479 \\
\hline Déficit & 0 & 0 & 0 & 0 & 0 & 26 & 142 & 128 & 62 & 0 & 0 & 0 & 358 \\
\hline Superávit & 17 & 22 & 2 & 4 & 0 & 0 & 0 & 0 & 0 & 0 & 0 & 0 & 45 \\
\hline
\end{tabular}

PEGO

Tipologia: $\mathrm{B}^{\prime} \mathrm{B}_{1}, \mathrm{~s}_{2} \mathrm{~b}_{4}^{\prime}$

T. media ETP

Precip.

Déficit

Superávit

$\frac{E}{10,4} \frac{F}{11,2} \frac{M}{13,0} \frac{A}{15,6} \frac{M}{18,6} \frac{J}{23,2} \frac{J}{25,4} \quad \frac{A}{25,7} \frac{S}{22,6} \frac{O}{18,2} \frac{N}{14,6} \frac{D}{10,9} \frac{\text { Año }}{17,4}$

$\begin{array}{lllllllllllll}20 & 23 & 37 & 57 & 89 & 138 & 159 & 149 & 106 & 69 & 38 & 22 & 907\end{array}$

$\begin{array}{lllllllllllll}90 & 76 & 72 & 85 & 62 & 38 & 6 & 23 & 79 & 196 & 117 & 112 & 956\end{array}$

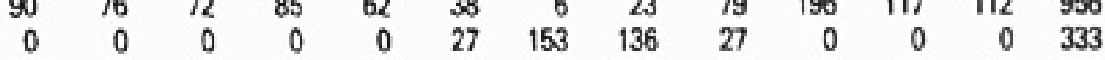

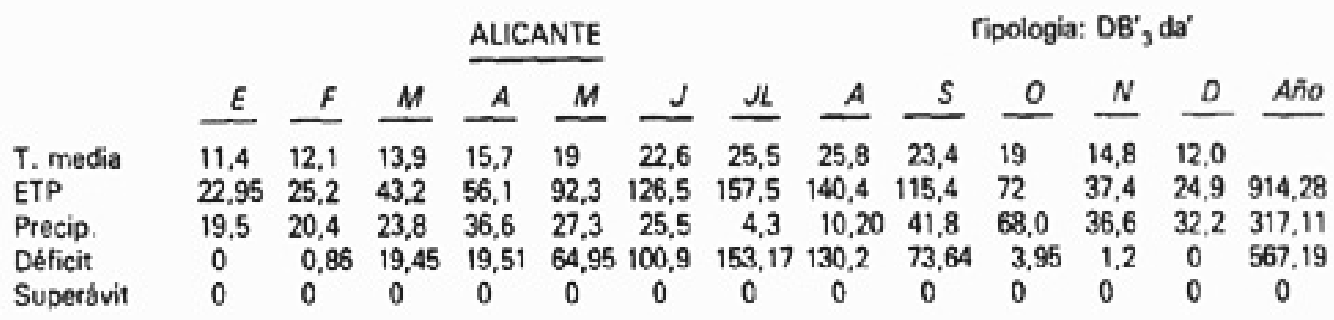

NOVELDA Tipologia: $\mathrm{DB}_{3}{ }_{3} \mathrm{db}_{4}$

$\begin{array}{llllllllllllll}\text { T. media } & 10,7 & 10,9 & 12,1 & 14,8 & 18,4 & 22 & 26 & 26,2 & 23,3 & 18,6 & 13,8 & 10,3 & \\ \text { ETP } & 22,95 & 25,2 & 33,99 & 52,8 & 88,56 & 122,76 & 161,25 & 157,95 & 115,4 & 69,12 & 35,3 & 19,92 & 905,2\end{array}$

$\begin{array}{llllllllllllll}\text { Precip. } \quad 25,1 & 19,3 & 26,7 & 33,7 & 27,2 & 28,5 & 5,0 & 11,5 & 32,12 & 44,2 & 27,4 & 28,3 & 309,1\end{array}$

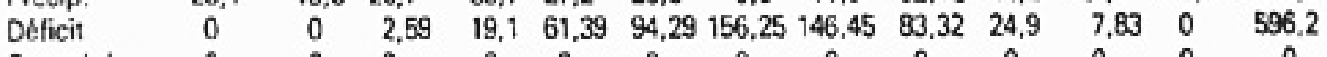

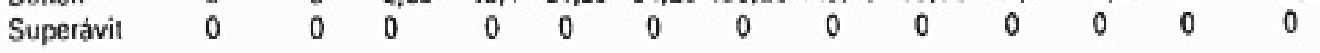

\begin{tabular}{|c|c|c|c|c|c|c|c|c|c|c|c|c|c|}
\hline & \multirow[b]{2}{*}{$E$} & \multirow[b]{2}{*}{$F$} & \multirow[b]{2}{*}{$M$} & \multicolumn{2}{|c|}{ ORIHUELA } & \multirow[b]{2}{*}{$d$} & \multirow[b]{2}{*}{ 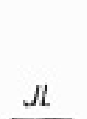 } & \multicolumn{6}{|c|}{ Tipologila: $\mathrm{EB}_{3} \mathrm{da}^{\circ}$} \\
\hline & & & & $A$ & $M$ & & & $A$ & $s$ & 0 & $N$ & $D$ & Año \\
\hline T. Media & 10.6 & 11,8 & 14,7 & 16.8 & 20.3 & 23,5 & 26.6 & 26,8 & 24,6 & 19,3 & 14,6 & 11,3 & 18,4 \\
\hline ETP & 18 & 23 & 43 & 68 & 100 & 134 & 169 & 164 & 119 & 72 & 35 & 22 & 962 \\
\hline Precip. & 25 & 20 & 15 & 42 & 25 & 17 & 4 & 9 & 30 & 47 & 26 & 34 & 294 \\
\hline Deficit & 0 & 0 & 12 & 21 & 75 & 117 & 165 & 155 & 89 & 25 & 9 & 0 & 668 \\
\hline Superávit & 0 & 0 & 0 & 0 & 0 & 0 & 0 & 0 & 0 & 0 & 0 & 0 & 0 \\
\hline
\end{tabular}


[74]

en la provincia, se puede establecer en el límite de los $8^{\circ}$ de enero» ${ }^{9}$.

El sector litoral se caracteriza por un invierno templado y verano caluroso. En la misma costa la media de enero es de $10-12^{\circ}$ en la Marina (Benidorm), Bajo Vinalopó (Elche) y Bajo Segura (Torrevieja), mientras en agosto se eleva a 25-27,5 . También en las sierras de la Marina (Callosa de Ensarriá) a una altitud de $247 \mathrm{~m}$. la media de enero está incluida en el intervalo, lo mismo que Benisa a un nivel de 300 $\mathrm{m}$.

Las condiciones se modifican enteramente en las sierras y llanos interiores. En las áreas con altitud superior a los $400 \mathrm{~m}$. la temperatura media de enero no alcanza el nivel de los $8^{\circ}$ : Alcoy, 7,4 $4^{\circ}$; Castalla, 5,5 y Villena, 5,9 . Son rasgos de inviernos fríos de naturaleza continental que se manifiesta de forma rápida a partir del Vinalopó Medio, donde Monforte a $230 \mathrm{~m}$. de altitud registra en enero $11^{\mathrm{o}}$, mientras Villena, Alto Vinalopó, a $505 \mathrm{~m}$., presenta rasgos netamente continentalizados que enlazan perfectamente con las condiciones de la Meseta.

Tales valores medios climatológicos tienen escaso significado sobre el desarrollo de los cultivos. En cambio, las temperaturas extremas ejercen una influencia más directa sobre sus posibilidades, lo mismo que las extremas absolutas que son tan perjudiciales como las propias heladas que el período frío entraña; pero el régimen de éstas $\mathrm{y}$, sobre todo, la primera y última del período alcanzan vital importancia.

Su período máximo está localizado en los llanos interiores y se extiende en la Hoya de Castalla (Ibi) desde el 24 de octubre al 4 de mayo, mientras el Alto Vinalopó (Villena) las soporta desde el 23 de octubre al uno de abril. Como todo el proceso térmico descrito, la intensidad se reduce hacia la costa. El período libre de heladas aumenta en función de la menor altitud y continentalidad hasta conseguir los máximos valores en el sector meridional de la Marina y en el área de la capital que las ha soportado de diciembre a mediados de febrero.

Tales mínimas, aunque no llegan a fuertes descensos «sí pueden causar daños en ciertos cultivos hortícolas (alcachofas) y frutales (almendro) que en la comarca del Bajo Vinalopó suele florecer desde principios de febrero» ${ }^{10}$, cuando el período libre de heladas no aparece garantizado hasta abril. Período de casi igual duración en el Bajo Segura, pero con un mayor número de registros por su continua propensión [75] «a las inversiones térmicas»» ${ }^{11}$, y éste es un factor limitativo que no está vencido en su totalidad provocando irregularidad productiva difícil de corregir.

Las cantidades anuales de lluvia son escasas por lo general, desiguales en su distribución estacional y geográfica y de elevadas irregularidades interanuales. Los valores extremos aparecen en Pego con $956 \mathrm{~mm}$. y Guardamar de Segura con 271 $\mathrm{mm}$. Existen notables diferencias entre un norte ciertamente lluvioso, cuya frontera meridional suele situarse en Benisa, donde se recogen cantidades superiores a los $500 \mathrm{~mm}$. y un Sur muy seco que no alcanza los $300 \mathrm{~mm}$. Entre ambos sectores se intercalan la Serranía de Alcoy, que recibe entre 450 y $500 \mathrm{~mm}$., y la zona de los

\footnotetext{
9 LÓPEZ GÓMEZ, A. «El clima», en LÓPEZ GÓMEZ, A. y ROSSELLÓ VERGER, V.Ma. Geografía de la Provincia de Alicante. Alicante, 1978, pág. 107.

10 GOZÁlVEZ PÉREZ, V. El Bajo Vinalopó: Geografía Agraria. Universidad de Valencia. Valencia, 1977, pág. 27.

${ }^{11}$ Según los datos de la C.H.S. referidos a Elche en el período 1954-1974, el total de días de heladas fue de 25, comprendidos entre diciembre y abril. En Orihuela para el mismo período y fuente, el total de días de heladas se elevó a 191 comprendidos entre noviembre y marzo.
} 
llanos interiores (Alto y Medio Vinalopó; Hoya de Castalla) que obtiene cantidades entre 300 y $400 \mathrm{~mm}$.

Como la aptitud agrícola y ganadera de un lugar depende no sólo de la cantidad anual de lluvias, sino también de la época del año en que normalmente llegan, interesa conocer su régimen pluviométrico puesto que tiene mayor importancia y significación que el total. De esta forma, el año meteorológico presenta dos máximos bien diferenciados: el primero, más significativo y con máximo de octubre, está centrado en otoño y acapara por sí solo casi el $40 \%$; el segundo se establece en la primavera, lo cual determina que el conjunto de ambas estaciones llegue a reunir el $64 \%$ de las lluvias, es decir, casi las dos terceras partes recibidas en sólo la mitad de tiempo. Además, tales cantidades son apenas suficiente para la explotación agraria que sólo se asegura mediante cultivos que cumplen su ciclo vegetativo antes de que se inicie la aridez estival o mediante árboles o arbustos que aprovechan las aguas profundas.

Esta pequeña pluviometría mal repartida y agravada por las irregularidades, es el primer factor limitativo de la producción agraria que a diferencia de la temperatura sí se puede corregir. Por esto, ante la necesidad imperante de aprovechar las favorables condiciones térmicas, a la vez que la revolución en las posibilidades y las técnicas de producción, se propicia la transformación del secano en regadío que obliga al agricultor a romper con el marco propio donde había desarrollado su vida y asentado el policultivo de secano.

La necesidad de agua requerida para el desarrollo de los cultivos se expresa, según Thornthwaite, bajo el término de Evapotranspiración [76] potencial (ETP). El autor introduce la idea de que por término medio los suelos son capaces de retener, como máximo, 100 milímetros de lluvia. Cuando la precipitación mensual es superior a la ETP correspondiente el suelo va almacenando dicha cantidad (variación de la reserva) hasta obtener, como máximo, los $1001 \mathrm{~m} 2$ indicados (reserva). Si el balance sigue siendo positivo, se produce superávit de agua que se manifiesta en la escorrentía superficial. Pero, cuando la ETP es superior a la precipitación mensual respectiva, el suelo va cediendo sus reservas hasta su total utilización. En estos momentos la ETP y la ERT (real) son iguales mientras exista reserva en el suelo. Si se agota la reserva, la ETR real es sólo la cantidad de agua recibida en el mes. Ahora el balance hídrico es negativo y el déficit de agua es la diferencia entre la ETP y la precipitación mensual correspondiente (mes árido). Todo esto nos permite definir numéricamente la importancia de la sequía, los períodos en los cuales se necesita agua y valorar la cantidad que se debe verter en las zonas de regadío (Cuadro 2).

La aridez se debe tanto a las altas temperaturas como a la escasa precipitación asociada a las bajas temperaturas. Cuando es producto de altas temperaturas, el clima presenta mayores beneficios al agricultor, puesto que el número de días de heladas es reducido, el período vegetativo largo, las plantas reciben más calor, crecen más deprisa y el número de cultivos aumenta. En consecuencia, el nuevo parámetro es el mayor valor indicativo de las limitaciones que el clima por sí solo impone a la actividad agraria.

Todos los municipios de la provincia demandan una necesidad de agua superior a los 700 milímetros anuales. La ETP aumenta desde las zonas del interior (Ibi, $712 \mathrm{~mm}$.) y serrana (Torremanzanas, $738 \mathrm{~mm}$.) a la costa (Villajoyosa, 917 $\mathrm{mm}$.). Según el grado de humedad el marco provincial se encuentra determinado por dos zonas climáticas diferentes. El sector propiamente húmedo del tipo $\mathrm{B}_{1} \mathrm{~B}_{3}{ }_{3} \mathrm{~s}_{2} \mathrm{~b}_{4}$ comprende el pequeño rodal de Pego y las sierras más elevadas. El superávit de 382 
mm. y el déficit de 333 se distribuyen de octubre a abril y de junio a septiembre, respectivamente.

Los climas secos $\left(C_{1} D E\right)$ se extienden por el resto provincial, pero la dureza es mayor en base al menor superávit y los mayores déficit y número de meses. Así, Benisa (Marina) se incluye dentro del tipo $\mathrm{C}_{1} \mathrm{~B}_{2} \mathrm{da}$ ' en el cual se comprueba un período con superávit de $68 \mathrm{~mm}$. (diciembre-abril) y falta en los meses de junio a septiembre (340 mm.). El sector semiárido (D) es el más extendido. Dentro de él aparecen claras diferencias con respecto a las citadas variables. Por un lado, Alcoy obtiene un superávit en base a su mayor precipitación; particularidad no constatada en ninguna otra comarca, lo cual manifiesta que el conjunto [77] podría estar integrado en el subtipo $\mathrm{C}_{1}$ enlazando con la zona de Benisa. Por otro, que en el conjunto Villena-Jijona la efectividad de las precipitaciones es mayor al no presentar nada más que cuatro meses áridos y el déficit no rebasar los $360 \mathrm{~mm}$. Por último, que el área integrada por el Campo de Alicante y el Vinalopó Medio (Novelda) y Bajo (Elche) arroja un déficit de agua superior a los $560 \mathrm{~mm}$. y el número de meses áridos es de nueve. El subtipo árido (E) se centra en el Bajo Segura y su diferencia con el área próxima está en el mayor déficit (Orihuela, $668 \mathrm{~mm}$.). El resultado ha sido la constante idea de solución mediante los trasvases, hoy perpetuado mediante el denominado Aprovechamiento conjunto Tajo-Segura.

Hasta época reciente, las clasificaciones climáticas propuestas han estado casi siempre basadas en relacionar los elementos del clima y los cambios en la vegetación. Han adolecido, por lo tanto, de una correspondencia entre clima y cultivos. El sistema de Papadakis ha supuesto un cambio puesto que su base de clasificación es estrictamente agrícola, ya que define capacidad y posibilidades del clima de una zona en términos de los cultivos que en ella pueden desarrollarse. Los parámetros elegidos son: frío invernal, calor estival y la aridez extraídos de las temperaturas medias de las máximas, mínima, mínima absoluta y precipitaciones.

La combinación de los regímenes térmicos y de humedad determinan que la provincia se encuadre dentro del tipo mediterráneo, distinguiéndose dentro de la misma tres subconjuntos: Mediterráneo Marítimo (Pego), donde en secano se permiten la producción de cereales, otros cultivos de invierno, cultivos arborescentes mediterráneos (Vid, higueras, almendro) y en regadío, frutales caducifolios y hortalizas tempranas y tardías; Mediterráneo-Templado (Villena, Alcoy y Castalla), con cereales de invierno en secano y en regadío a base de manzano, peral y frutales caducifolios; Mediterráneo-Subtropical, extendido por el sector litoral (Alicante) y la zona más árida (Elche y Orihuela) que en secano permite cereales de invierno, cultivos arborescentes mediterráneos, y en regadíos algodón, cítricos, frutales caducifolios, hortalizas y en su variedad de invierno más benigno, incluso cultivos tropicales.

Así pues, a la hora de establecer el balance agronómico del clima como factor limitativo de la producción agraria en la provincia, es necesario destacar que la elevada aridez se contrapone a la suavidad del invierno litoral, base indispensable a la expansión de cultivos sensibles al frío; «de todos modos, es preciso resaltar que la explotación de este factor potenciado con el empleo de invernaderos y plásticos, cobra su mayor amplitud en las tierras tradicionalmente más desheredadas del litoral 
[78] murciano alicantino donde había contado más como rémora que ventaja para una cerealicultura magra y aleatoria» ${ }^{12}$.

\section{4.- DIFERENCIAS EN LA UTILIZACIÓN DEL SUELO}

Las condiciones naturales no son capaces de explicar totalmente las diferencias en la utilización del suelo. Los factores humanos tienen una importancia tan decisiva o más. Al finalizar 1975 la superficie física provincial se distribuía en la forma siguiente: labrada $52^{\prime} 32 \%$, no labrada $34^{\prime} 40 \%$ e improductiva $13{ }^{\prime} 28 \%$.

Las comarcas se agrupan por el valor de sus índices agrícolas según los diferentes intervalos, el aprovechamiento agrario preferente y los índices de regadío y barbecho (fig 1). Alcoy, Villena, Novelda, Denia, Villajoyosa, Elche y Orihuela son agrícolas, pero su grado de intensidad es muy diferente, oscilando del 82 '34\% de Orihuela al 53'04 de Alcoy. Las tres comarcas restantes son consideradas ganaderas: Pego con un índice del $65^{\prime} 63$, Callosa de Ensarriá con el 65'40 y Alicante con el $51^{\prime} 80^{13}$.

En realidad, lo que se pone de manifiesto con este tipo de Análisis no es sólo las diferencias internas que existen en cuanto a los hechos físicos, sino los profundos contrastes derivados de los propios humanos como: el aprovechamiento agrario dominante, las desigualdades comarcales de regadío y barbecho, el grado de mecanización, la estructura de las explotaciones, el rendimiento bruto por hectárea de superficie labrada y la densidad ganadera.

\section{a) Aprovechamiento agrario dominante}

La casi totalidad de las comarcas fundamentan su base productiva agrícola en los cultivos leñosos acaparando el $91{ }^{\prime} 87 \%$ en Denia y reduciéndose hasta el $53{ }^{\prime} 42 \%$ en Alicante. Sólo en Elche y Orihuela, donde se localizan los mayores índices de regadío, los cultivos herbáceos obtienen porcentajes superiores, 56'91\% y 50'84\% respectivamente, a los leñosos.

La característica principal de la evolución de la superficie labrada comarcal [79] ha sido doble: en primer lugar el continuo retroceso del espacio de secano, que ha pasado de 186.508 ha en 1975 a 174.434 en 1980, a la vez que el regadío aumentó del 117.944 a 124.543 ha; en segundo lugar el descenso de la superficie ocupada por los cereales de invierno, trigo, cebada, avena etc. La primera se extiende en base a la limitación impuesta por las precipitaciones mientras la expansión del regadío se basa en la utilización de los recursos hídricos subterráneos y al aprovechamiento conjunto del trasvase Tajo-Segura. La segunda está en relación a las condiciones hostiles del suelo, la topografía y la limitación hídrica unida al fuerte éxodo y escasa productividad, aumentando el terreno improductivo (1627 ha entre 1975 y 1977) o reconvirtiéndolo en plantaciones de cultivos leñosos de secano o regadío o en regadío hortícola.

Como consecuencia, el aprovechamiento agrario dominante del secano de las comarcas litorales se fundamenta en el almendro, debido a sus pocas exigencias

${ }^{12}$ GIL OLCINA, A. «Paisajes Rurales en la fachada Este de España» en Los paisajes rurales de España, op. cit., pág. 251.

${ }^{13}$ En el Campo de Alicante este índice se obtiene por los aportes de los valles marginales de Jijona y Busot que con extensiones superficiales de 19.800 ha y 5.203 ha, respectivamente, sólo cultivan 5.730 y 2.473 ha 
hídricas y a las favorables condiciones térmicas. Éste ocupa el segundo lugar en el Marquesat (Pego-Denia) y en Novelda para descender al tercero en las comarcas más interiores, Villena y Alcoy, con mayor persistencia de heladas. Su expansión es tan grande que ha llegado a extenderse por las tierras de regadío, incluso como monocultivo $^{14}$, en el caso de Elche con 5.107 ha, y, con menores extensiones en Alicante, 1989 ha y Villajoyosa 1.237 ha Resulta así que la superficie ocupada por esta especie de arbolado ha ido aumentando en cada uno de los recuentos temporales, pasando de las 51.832 ha de 1975 , de las que el $24^{\prime} 82 \%$ eran de regadío, a 65.136 en 1980 de las que el riego ocupa el $28^{\prime} 12 \%$. La vid ocupa el segundo lugar entre los cultivos tradicionales del secano, pero ésta, a diferencia del almendro, se concentra en el Alto y Medio Vinalopó (Villena y Novelda) y en Denia ocupando una extensión de 43.883 ha que se distribuyen: 8.043 como viñedo de mesa y 35.840 como productora de vino. Tal cantidad ha experimentado un alza en la superficie aprovechada puesto que la misma se eleva en 1980 a 44.841 ha pero su contribución es diferente ya que la uva de mesa desciende a 7.835 ha, mientras la de transformación alcanza 37.006 ha Además, a esta superficie es necesario añadir 15.478 ha de regadío, de las que 11.794 es de uva de mesa y el resto para transformación en vino.

El tercero de los aprovechamientos dominantes de secano está cifrado [80] en el olivar a pesar de la disminución que está sufriendo por la mano de obra y por encontrarse en zonas marginales de cultivo. Sus mayores extensiones ocupadas se encuentran en las comarcas de Alcoy y Villena con 10.996 y 7.776 has, respectivamente, seguido de lejos por Pego (cultivo dominante), Alicante y Novelda. En 1975 la superficie provincial alcanzaba la cantidad de 28.685 ha de las que 2.595 el 9’04\% estaban en regadío. En 1980 el olivar ocupa 26.603 ha siendo el 9’01\% de regadío.

En la zona transformada por el riego los aprovechamientos dominantes cambian radicalmente entre las comarcas. Ya se ha indicado que el almendro ocupa las mayores extensiones de Villajoyosa a Elche. En el Bajo Segura (Orihuela) el cultivo dominante son los cítricos puesto que los naranjales ocupaban 8.053 ha y el limonero 6.736. Con la llegada de las aguas del trasvase Tajo-Segura la situación se ha modificado al incrementarse la superficie de limonero, entre 12 y 15.000 ha. Al poner en producción estos terrenos que hace diez años eran montes y algarrobos, la provincia de Alicante pasa a ocupar el primer lugar del país en superficie y producir la V. Baja entre el 25 y el 30\% de volumen nacional. Pero la exportación ha sufrido un revés muy considerable. Los aportes de Italia, Israel y Países norteafricanos, unido al aumento de la producción y la estabilidad del consumo ha provocado la caída de los precios, dejando de ser rentable para el agricultor. Y es que al ganarse dinero con este cítrico (40 ptas. en 1975) el empresario agrícola se volcó en él, aumentando la superficie al tiempo que no se buscaban nuevos mercados (países del Golfo Pérsico), haciendo en la actualidad incierto su futuro.

Las hortalizas cubrían una superficie de 22.728 ha. de las que el 93'89\%, casi la totalidad, estaban en regadío. Tal paisaje se encuentra muy localizado puesto que las dos comarcas meridionales acaparaban el 80'78\% del total y el 80'71 del espacio regadío. Dentro de este conjunto la alcachofa cubría una extensión de 10.000 ha

14 GOZÁLVEZ PÉREZ, V. «Tendencias recientes de la agricultura valenciana». Cuadernos de Geografía, 1979, n 25, pág, 160 «las plantaciones del Bajo Vinalopó no sólo responden a las ventajas comerciales de esta fruta, sino también a que es un cultivo bien adaptado por su escasa exigencia en mano de obra a una agricultura a tiempo parcial originado por el empleo industrial de Elche». 
disminuyendo con el tiempo hasta reducirse a 4.991 ha en 1980. La provincia pierde la hegemonía lograda en la década de los setenta aduciendo como causas más probables el agua contaminada y el cansancio de la tierra. Pero ¿cuál es la tendencia de la Vega Baja que ha visto caer la alcachofa y empieza a encontrar problemas con el limonero? Parece que el agricultor se orienta por las cosechas protegidas, algodón (en 1982 se sembrará un 30\% menos por escasez de agua para riego), trigo de regadío que ha ido en aumento en el conjunto provincial y que este año se ha sembrado mucho en la Vega, y maíz, todos ellos con precios garantizados y adecuados perfectamente en los ciclos de rotación.

Otro aprovechamiento dominante en el regadío aparece localizado [81] en el conjunto Pego-Denia-Callosa de Ensarriá, donde los agrios cubren una gran superficie destacando Denia con 5.168 ha de naranjos y mandarinas, el 80'36 de su espacio regadío, índice que se eleva al $84^{\prime} 07 \%$ si se hace extensivo a todos los cítricos. $^{15}$

\section{b) Desigualdades en regadío y barbecho}

Las grandes oscilaciones productivas del secano han obligado a sustituir el régimen pluviométrico descrito por uno hidrológico más acorde con el tiempo y la cantidad de agua demandada por los cultivos. Los embalses superficiales y el aprovechamiento de los recursos subterráneos han permitido la transformación en regadío del $38^{\prime} 74 \%$ de la superficie labrada provincial, porcentaje que se eleva al $41^{\prime} 65 \%$ al finalizar 1980 .

En 1975 el valor medio se conseguía por los aportes de Elche y Orihuela. Ninguna de las restantes comarcas lograba aquel nivel; sólo Callosa de Ensarriá, $37 ’ 71 \%$ se aproximaba mientras las demás obtenían índices inferiores al 30\% siendo realmente bajos en Alcoy, 6’90\% y en Villena 17’40\% (cuadro 3). La situación se

$$
\begin{gathered}
\text { CUADRO } 3 \\
\text { ÍNDICE DE REGADÍO Y BARBECHO }
\end{gathered}
$$

\begin{tabular}{|c|c|c|c|}
\hline & \multicolumn{2}{|c|}{ Regadio } & \multirow{2}{*}{$\frac{\text { Barbecho }}{1975}$} \\
\hline & 1975 & $\underline{1980}$ & \\
\hline ALCOY & 6’90 & 6’53 & $16 ’ 90$ \\
\hline VILLENA & $17^{\prime} 40$ & $19^{\prime} 75$ & 8’95 \\
\hline NOVELDA & $28^{\prime} 26$ & $42 ’ 49$ & $21 ’ 90$ \\
\hline PEGO & $28^{\prime} 62$ & $32 ' 58$ & $8^{\prime} 68$ \\
\hline DENIA & $29 ’ 31$ & $28 ’ 09$ & 2’19 \\
\hline VILLAJOYOSA & $32 ’ 97$ & $31^{\prime} 04$ & $9^{\prime} 48$ \\
\hline CALLOSA DE ENSARRIÁ & $37^{\prime} 71$ & $35^{\prime} 62$ & 3'83 \\
\hline ALICANTE & $33^{\prime} 22$ & $35^{\prime} 60$ & $26^{\prime} 71$ \\
\hline ELCHE & $86^{\prime} 41$ & $88^{\prime} 05$ & 8'48 \\
\hline ORIHUELA & $61 ’ 74$ & $69^{\prime} 52$ & $17^{\prime} 61$ \\
\hline PROVINCIA & $38^{\prime} 74$ & $41^{\prime} 65$ & $14^{\prime} 65$ \\
\hline
\end{tabular}

\footnotetext{
${ }^{15}$ INFORMACIÓN 26-8-82. «El agotamiento de numerosas fuentes que alimentaban a pequeños regadíos y la irreversible salinización de acuíferos subterráneos provoca en la comarca el declive de 6.000 ha de cítricos y el peligro de su extinción».
} 
Fuente: Análisis. ALICANTE. 1980. Elaboración propia.

modifica en 1980 ya que Villena [82], Novelda, Pego, Alicante, Elche y Orihuela elevan sus índices siendo muy sustanciales en el caso de Novelda y Orihuela, donde se incrementan en un 14'23 y 7'77 puntos, respectivamente. En el resto de este conjunto los porcentajes son inferiores y su valor nunca llega a ganar cinco puntos. $\mathrm{Su}$ factor limitativo, el agua, le encarece el coste de la producción y ésta sólo es rentable con cultivos de precio alto, uva de mesa y limoneros, base de la expansión del regadío de Novelda y Orihuela.

En Alcoy, Denia, Callosa de Ensarriá y Villajoyosa el porcentaje de superficie regada desciende en 1980. En la primera, donde la precipitación alcanza mayor efectividad, el índice permanece prácticamente estabilizado puesto que los recursos hídricos no son obstáculos para atender a la superficie transformada ${ }^{16}$. En el resto la escasez de recursos y la progresiva salinización de los caudales determinan reducción del porcentaje de la superficie regada, aunque tales valores están muy por encima de la media nacional, $13 \%$.

Pero no sólo el índice de regadío motiva contrastes internos. También lo hace la superficie comarcal que cada año permanece inactiva y con nulo o casi nulo provecho. El labrador alicantino cede anualmente al barbecho, por causa de la aridez, cotas que van del 2'19\% del terreno labrantío en Denia, donde los cultivos leñosos acaparan el $91{ }^{\prime} 87 \%$ de este espacio, al $26^{\prime} 71 \%$ en el campo de Alicante, donde los cultivos herbáceos alcanzan el $46{ }^{\prime} 57$, obteniéndose un índice medio provincial de 14'65 (Cuadro 4).

\section{c) Producto bruto por superficie labrada}

Los rendimientos son el resultado de los caracteres físicos y humanos. Como la vid y el almendro son dos productos básicos en la economía agraria alicantina y la diferenciación comarcal se fundamenta en la producción agrícola el rendimiento medio anual del trigo, almendro y vid para vinificación en secano y regadío es un parámetro capaz de justificar sus desigualdades.

El mayor valor del trigo en secano se localiza en Pego entre 13 y 14 Qm/ha y el mínimo en Orihuela con 95 Qm/ha El modelo se repite en los cultivos leñosos de secano al conseguirse en Pego el techo de los mismos, 10 Qm/ha para el almendro y 28 Qm/ha para la vid, cuando en el espacio de Villajoyosa a Orihuela se obtienen los menores. Así, la comarca con mayor precipitación total anual y efectividad de la [83]

\footnotetext{
${ }^{16}$ INFORMACIÓN 30-5-1982. Según el IRYDA la recarga total de los sistemas en los que se ubica la comarca de la Montaña alicantina asciende a $220 \mathrm{Hm}$ cúbicos al año.
} 


\section{CUADRO 4 \\ TIPOLOGIA COMARCAL AGRARIA ALICANTINA}

\begin{tabular}{|c|c|c|c|c|c|}
\hline$x<\mathrm{h}<100$ & $\begin{array}{l}\text { Agrowechumiacto dominunts } \\
\text { culthos hertbiceos snuales }\end{array}$ & $10<x$ & $20<10<70$ & $10<30$ & ORIKUELA - P.B.61.365 \\
\hline \multirow[t]{2}{*}{$60<4<\infty$} & $\begin{array}{l}\text { Aprowechamiento deminants } \\
\text { eultivos lestosos }\end{array}$ & $\begin{array}{c}75<1<100 \\
4<\pi 5\end{array}$ & $\begin{array}{l}20<\omega<\omega 0 \\
20<\omega<\infty\end{array}$ & $\begin{array}{l}10<30 \\
10<30\end{array}$ & $\begin{array}{l}\text { OENEA - P.8. } 36.672 \\
\text { VLLA JOYOSA - P.B. } 31.696 \\
\text { NOVELOA - P. B. } 41.500\end{array}$ \\
\hline & $\begin{array}{l}\text { Agrovechumiersto dorninsents } \\
\text { culthos herbdcoos envalts }\end{array}$ & $b<75$ & $\pi<10<100$ & $4 .<30$ & ELCHE - P.B. SS 326 \\
\hline $40<14<00$ & $\begin{array}{l}\text { Aprovechurriento docrinento } \\
\text { cultivos lofiosos }\end{array}$ & $\begin{array}{c}75<k<100 \\
1,<\pi 5\end{array}$ & $\begin{aligned} 1 & <20 \\
20 & <1 .<40 \\
1 & <<20\end{aligned}$ & $\begin{array}{l}1,030 \\
1,<30 \\
1,<30\end{array}$ & $\begin{array}{l}\text { VULENA - P.B. } 20.400 \\
\text { AUCANTE - P.B. } 35.223 \\
\text { ALCOY - P.B. } 25.500 \\
\end{array}$ \\
\hline $4<40$ & $\begin{array}{l}\text { Aprovechemiento dorvingnts } \\
\text { culivios lalloses }\end{array}$ & $x<10<100$ & $20<4<40$ & $1,<30$ & $\begin{array}{l}\text { CALLOSA - P.B.SS.111 } \\
\text { PECO - P.0. } 32.300\end{array}$ \\
\hline
\end{tabular}

misma asegura más sus rendimientos y la variabilidad interanual se reduce al tiempo que las más áridas consiguen los más pequeños.

Los mismos cultivos, paliado su principal factor limitativo, también provocan desiguales rendimientos, aunque éstos se elevan muy considerablemente frente al secano. Y es que el rendimiento, al ser la síntesis de la interrelación climática, cuyos golpes de calor o frío no han podido ser aun paliados, la edáfica y la técnicoagronibirnica, provocan claras diferencias en el producto bruto por hectárea labrada entre las comarcas.

En regadío, el trigo obtiene un rendimiento medio provincial de $35 \mathrm{Qm} / \mathrm{ha}$, oscilando su valor entre los 47 de Elche y los 25 Qm/ha del conjunto, Alcoy, Villena, Pego y Alicante. En el almendro parecen existir dos espacios diferenciados: por un lado la zona de Alcoy, Villena y Novelda con producción media de 13 Qm/ha y por otro el sector litoral de Callosa de Ensarriá a Orihuela, con 14 Qm/ha, precisamente donde se encuentran las mayores superficies ocupadas por él. En cambio, los rendimientos de vid para vinificación son mayores en el área interior de Alcoy, Villena y Novelda con producción media de $13 \mathrm{Qm} / \mathrm{ha}$ y por otro el sector litoral de Callosa de Ensarriá a Orihuela con 14 Qm/ha, precisamente donde se encuentran las mayores superficies ocupadas por él. En cambio, los rendimientos de vid para vinificación son mayores en el área interior de Alcoy, Villena y Novelda con 32 Qm/ha y menores en Elche y Orihuela, $24 \mathrm{Qm} / \mathrm{ha}$

Pero los cuadros de índices, a los que es necesario unir el de mecanización y la estructura de las explotaciones, y el rendimiento bruto por hectárea explican igualmente las diferencias internas que existen en cuanto a hechos humanos. El regadío pone de manifiesto que los mayores porcentajes medios se localizan en las comarcas meridionales de mejores condiciones térmicas, edáficas y topográficas, pero de más adversa precipitación, y el menor en la zona serrana. Todo ello determina [84] que el producto bruto agrícola provincial por hectárea labrada sea, al finalizar 1975, de 42.615 pesetas. Sin embargo, esta cifra engloba sensibles diferencias comarcales a causa del índice de regadío, los cultivos aprovechados por el suelo, los índices de utilización de cultivos herbáceos de secano y regadío ${ }^{17}$ y los

\footnotetext{
${ }^{17}$ El índice de utilización de secano viene determinado por el cociente entre la superficie de cereales de invierno más la de las plantas barbecheras y la superficie total de secano. El valor medio provincial es de 0.2 y el mismo oscila entre el 0.01 de Elche, y el 0.43 de Alcoy. El índice de regadío es el
} 
propios rendimientos cosechados. Orihuela, que ocupa en regadío el $61^{\prime} 74 \%$ de su espacio agrícola, que utiliza el suelo con cultivos del alto precio y que obtiene altos rendimientos, consigue 61.985 pesetas de producto bruto agrícola. En cambio, Alcoy, que labra el 6'9, utiliza el suelo con aprovechamiento preferente de olivar y tiene menores rendimientos en los demás cultivos, sólo obtiene 25.500 pesetas.

No obstante, este valor medio comarcal encierra a la vez nuevos contrastes que se manifiestan al tratar de comprobar la contribución de las superficies de regadío y secano. Así, Orihuela obtiene en secano el menor valor, 12.500 pesetas alcanzando el máximo provincial por las 92.600 pesetas que produce en bruto cada hectárea de regadío, cantidad aún superada por Novelda con ganancias brutas de 108.900 pesetas. Todo esto conduce a la formulación de una nueva tipología agraria comarcal alicantina que refleja profundamente los contrastes internos de su producción en base a factores físicos y humanos (Cuadro 4).

Sin embargo, esta clasificación se puede modificar cada vez que su factor limitativo sea paliado o imposible de atender sus demandas. Así, el índice de regadío se verá incrementado en el área de Alicante y el Medio Vinalopó al poder transformarse más de 8.000 hectáreas con las aguas residuales de la capital ${ }^{18}$, modelo que se intenta introducir en las comarcas próximas de mayor densidad demográfica. $\mathrm{O}$, también, el índice aumentará con las dotaciones de agua de la primera fase del trasvase Tajo-Segura, caso de las comarcas meridionales y el campo de Alicante, pero no con la de la segunda fase, que asigna $70 \mathrm{Hm}$. cúbicos a la provincia, puesto que alguna zona muy afectada por las disponibilidades de sus recursos, Medio Vinalopó, no podrá utilizarla en este fin. Y es que, al ser necesario elevarla 300 metros más (ya ha sido elevada desde el embalse de Bolarque a Murcia entre $400 \mathrm{y}$ $500 \mathrm{~m}$.) repercutiría considerablemente [85] en el coste de los productos, y su utilización, en el caso de que llegara, sería para abastecimiento de su población y usos industriales ${ }^{19}$.

En resumen, para poder utilizar el Análisis como fuente agraria (a pesar de las limitaciones indicadas) debería cumplimentarse todos los años y explicar al mismo tiempo varios de sus conceptos. Se vería entonces la dinámica agraria de cada uno de sus índices comarcales, tendencias de cultivos, introducción de los nuevos, cambio en el uso del espacio, grado de utilización en secano y regadío y producto bruto por hectárea de superficie labrada, ya que su oscilación es el mejor termómetro indicativo de la repercusión del año meteorológico y la propia acción humana sobre la actividad agraria. [86]

cociente entre la superficie ocupada por el regadío menos la no ocupada y la superficie física transformada. En la provincia dicho valor se eleva a 0 '79, siendo sus índices extremos el 0.17 de Villajoyosa y el 1.08 de Orihuela.

${ }^{18}$ INFORMACIÓN 9-5-82. El contrato privado del compraventa de aguas residuales depuradas que han suscrito con EMARASA estipula un caudal de 350 1/seg. con un mínimo anual de tres millones de metros cúbicos.

${ }^{19}$ MORALES, A. y JUÁREZ, C. «Cambios en los usos del agua». Estudios geográficos 1981, no 165 pág 389. A pesar de todo las aguas del trasvase serán rentables para las provincias de Alicante y Murcia en función de los usos a que se destinen. En cuanto las primeras aguas han empezado a circular por él, su utilización ha sido, en principio, para el abastecimiento de las poblaciones comprendidas en el triángulo cuyos vértices son: Cieza (Murcia), Altea (Alicante) y Águilas (Murcia), y en segundo lugar para sus usos industriales. 


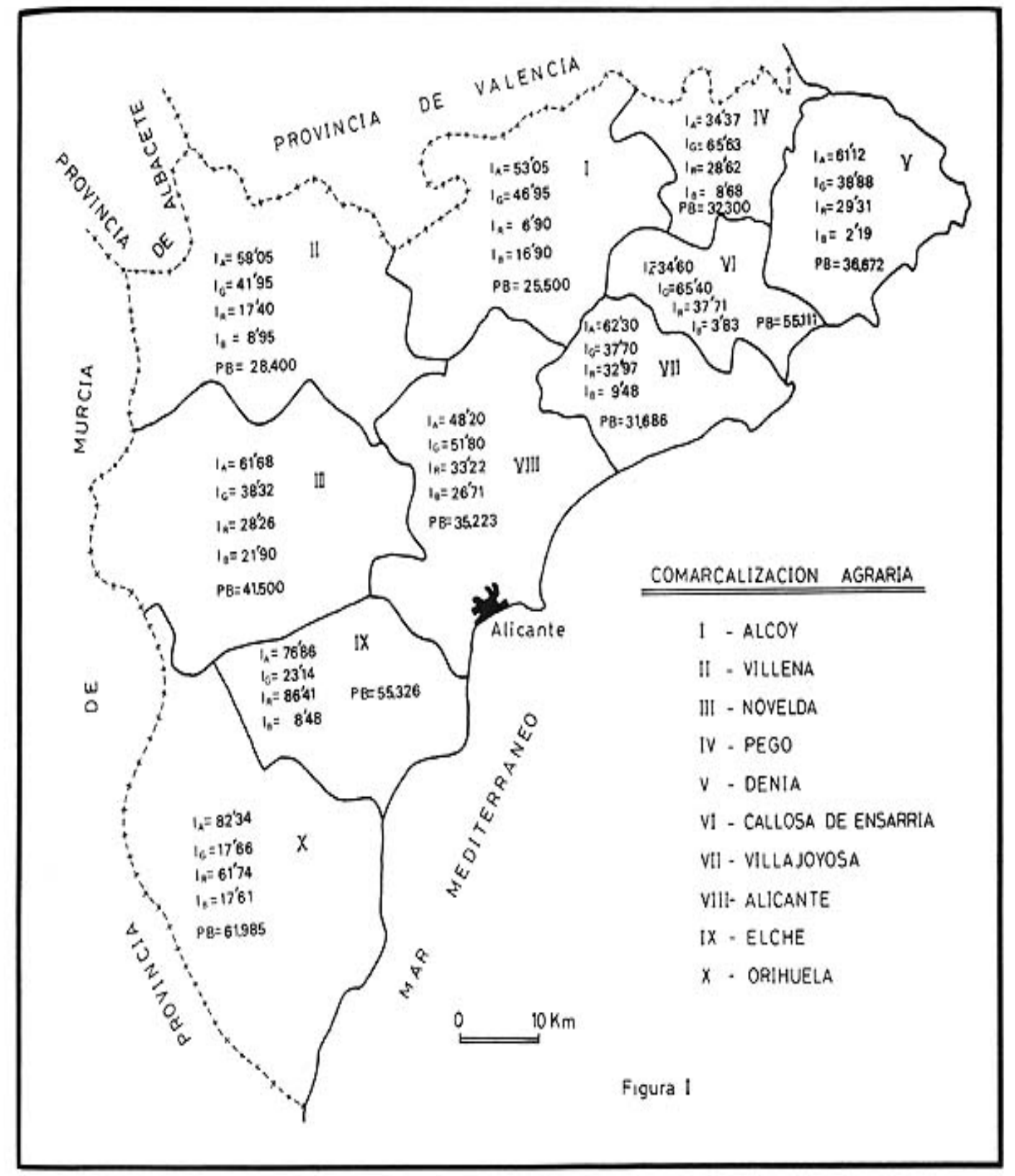

IV 